\title{
Health risk assessment of various metal(loid)s via multiple exposure pathways on children living near a typical lead-acid battery plant, China
}

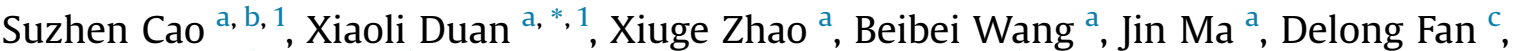 \\ Chengye Sun ${ }^{\mathrm{d}}$, Bin $\mathrm{He}^{\mathrm{b}}$, Fusheng Wei ${ }^{\mathrm{b}, \mathrm{e},{ }^{* *}, \text { Guibin Jiang }}{ }^{\mathrm{b}}$ \\ a State Key Laboratory of Environmental Criteria and Risk Assessment, Chinese Research Academy of Environmental Sciences, Beijing 100012, China \\ ${ }^{\mathrm{b}}$ Research Center for Eco-Environmental Sciences, Chinese Academy of Sciences, Beijing 100085, China \\ c School of Civil and Environmental Engineering, University of Science and Technology Beijing, Beijing 100083, China \\ ${ }^{\mathrm{d}}$ National Institute of Occupational Health and Poison Control, Chinese Center for Disease Control and Prevention, Beijing 102206, China \\ e China National Environmental Monitoring Center, Beijing 100012, China
}

\section{A R T I C L E I N F O}

\section{Article history:}

Received 17 September 2014

Received in revised form

14 December 2014

Accepted 7 February 2015

Available online 14 February 2015

\section{Keywords:}

Children

Heavy metal(loid)s

Lead-acid battery

Exposure pathways

Health risks

\begin{abstract}
A B S T R A C T
Manufacture of lead-acid batteries is of widespread interest because of its emissions of heavy metals and metalloids into environment, harming environmental quality and consequently causing detrimental effects on human health. In this study, exposure pathways and health risks of children to heavy metal(loid)s ( $\mathrm{Pb}, \mathrm{Cd}, \mathrm{As}$, etc) were investigated based on field sampling and questionnaire. $\mathrm{Pb}$ was one of the most abundant elements in children's blood, with an elevated blood lead level of $12.45 \mu \mathrm{g} \mathrm{dL}^{-1}$. Soil/ dust and food were heavily polluted by targeted metal(loid)s. Food ingestion accounted for more than $80 \%$ of the total exposure for most metal(loid)s. The non-cancer risks to children were 3-10 times higher than the acceptable level of 1 , while the cancer risks were 5-200 times higher than the maximum acceptable level of $1.0 \times 10^{-4}$. The study emphasized the significance of effective environmental management, particularly to ensure food security near battery facilities.
\end{abstract}

() 2015 Elsevier Ltd. All rights reserved.

\section{Introduction}

Refined lead is the main raw material of lead-acid batteries, which consumed up to $84 \%$ of lead consumption (Tian et al., 2014). Previous studies found that the estimated lead emission from leadacid battery industries accounted for more than $80 \%$ before 2001 and 3\% after 2001 to the total lead emission in the Greater Cairo area (Safar et al., 2014). With the rapid development of battery industries including manufacturing and recycling (Chen et al., 2009; Gottesfeld and Pokhrel, 2011), China has become the largest producer, consumer, and exporter of lead-acid batteries in

\footnotetext{
* Corresponding author. State Key Laboratory of Environmental Criteria and Risk Assessment, Chinese Research Academy of Environmental Sciences, Beijing 100012, China.

** Corresponding author. Research Center for Eco-Environmental Sciences, Chinese Academy of Sciences, Beijing 100085, China.

E-mail addresses: duan_jasmine@126.com (X. Duan), wfs851317@163.com (F. Wei).

1 Author contributions: These authors contributed equally to this work.
}

the world (Chen et al., 2009; Sun, 2012). Unfortunately, many leadacid battery factories in China are in operation without a production permission certificate (http://news.xinhuanet.com) and represent a large proportion of local pollution and human lead $(\mathrm{Pb})$ poisoning incidents.

It was reported that $\mathrm{Pb}$ poisoning incidents from 2009 to 2013 in China affected more than 5000 children, and a portion of them were related to lead-acid battery industry (Chuang et al., 2008; Gao and Xia, 2011; Ji et al., 2011). Besides Pb, other metals or metalloids such as cadmium (Cd), arsenic (As) and chromium (Cr) could also be largely released, since they are associated elements in leadcontaining ores, impurities in lead alloys, or frequently used as additives in the molding and casting processes of the industry (Onianwa and Fakayode, 2000). These toxic ingredients would enter into the environment via soil/dust, drinking water, ambient air and food (Granero and Domingo, 2002; Wang and Stuanes, 2003), and into the body through dermal contact, inhalation and ingestion exposure pathways.

Previous studies conducted around battery-related factories mostly focused on $\mathrm{Pb}$ pollution in the surroundings (Chen et al., 
2012; Onianwa and Fakayode, 2000), lead exposure of occupational workers (Ahmed et al., 2008; Chuang et al., 2008) or children (Chen et al., 2012; Haefliger et al., 2009; Kaul et al., 1999; Kuijp et al., 2013) living in the vicinities of the plants. However, the exposure and combined health risks from other heavy metal(loid)s such as As, Cd, and $\mathrm{Cr}$ were rarely studied. Exposure to these heavy metals and metalloids would result in severe impairment in humans such as kidney dysfunction, lung cancer, or neurological effects (Chiodo et al., 2004; He et al., 2009; Koller et al., 2004). Children are more prone to heavy metal(loid)s poisoning due to child-specific physiological and behavior patterns (Fitzgerald et al., 1998; Fowler, 1993). Children's health-related incidents such as lead or cadmium poisoning have attracted nationwide attention (Gao and Xia, 2011), particularly around lead-acid battery areas (Fan et al., 2010; Hu et al., 2002). Therefore, assessing the aggregated risks of exposure to various heavy metal(loid)s via different environmental media and their main pathways in areas where lead-acid batteries are common would be of great importance for providing a rational basis to protect children's health.

The objectives of the present study were to (1) quantify the concentrations of 12 metals and metalloids in water, food, air, soil/ dust around a typical lead-acid plant in China; (2) quantify the exposure levels and contributions from each medium; and (3) estimate children's health risks due to exposure to heavy metal(loid)s from each medium. Hazard quotients (HQ) and the incremental lifetime cancer risk (ILCR), characterizing the non-cancer and cancer risk, respectively (Granero and Domingo, 2002; Mari et al., 2009), were used in the risk assessment. Monte Carlo simulation was conducted (Mari et al., 2009), to determine the inherent uncertainty in predicted risks resulted from exposure assessment.

\section{Materials and methods}

\subsection{Study area}

A typical lead-acid battery plant located in a suburban area of southeast Hunan province was used as a model. The plant was a typical small private battery manufacturer with several bungalows and workers. Like the other 1800 small private lead-acid battery manufactures in China (accounting for $90 \%$ of the total enterprises), some procedures in the selected plant including powder, paste and plate separation processes were conducted without automation and closed operation. The wastewater treatment mainly relied on chemical precipitation, due to the simple facilities. Additionally, no other enterprises or industrial activities were located in the study area, and no highways or heavy traffic volumes existed in the vicinity. There was a primary school situated close to the manufacturing area. The children who attended the school mostly lived near the plant, with a distance of $898 \mathrm{~m}$ between the manufacturing area and the residence (ranging from 454 to $1284 \mathrm{~m}$ ). The raw materials used in the battery plant were not considered in this study.

\subsection{Sample collection and analysis}

\subsubsection{Human behavior pattern survey}

After the approval from ethics committee of the National Center for Disease Control, this research was then conducted, mainly focusing on the children in the primary school. Before the survey and sampling, written informed consents by the participants and their guardians, concerning the behavior pattern survey and the household sampling were obtained from 64 participants, who were native-born and aged 5-8 years old. A questionnaire-based survey was then conducted among the participants to determine the key risk factors, such as dietary behavior, daily activity patterns and lifestyles.

\subsubsection{Field sampling}

Blood samples were taken from the 64 participants to characterize the internal exposure level. For each child, $4 \mathrm{~mL}$ of cubital fossa venous blood was collected (Liu et al., 2009) and stored at $-25{ }^{\circ} \mathrm{C}$ until analysis.

18 volunteers were randomly selected to participate in the environmental survey on their families. A total of 18 tap water (drinking water) samples (1 L) were collected in acid-washed polyethylene bottles from the 18 volunteers' families. Another 2 typical samples were respectively collected from kitchen and classroom of the school to truly reflect the water quality consumed by the children. The water samples were stored at $-20^{\circ} \mathrm{C}$ until analysis after adding two drops of $65 \%$ concentrated $\mathrm{HNO}_{3}$.

4 samples from the school and 18 samples $(1 \mathrm{~kg})$ from the courtyards of the children's homes were collected from the upper soil layer $(0-20 \mathrm{~cm})$ in undisturbed locations, using the established sampling method (Zhang et al., 2010). Additionally, 4 dust samples from the floor and stairs of the school classroom and 18 indoor dust samples from the children's homes were collected using a dust-free brush. Each dust sample was mixed with 4 or 5 sub-samples.

2 and 18 samples of 24 -h indoor $\mathrm{PM}_{10}$ from the school and volunteers' homes were respectively collected on pre-combusted $\left(500{ }^{\circ} \mathrm{C}, 6 \mathrm{~h}\right)$ quartz microfiber filters (Munktell In C., Sweden) using an established sampling method (Cao et al., 2014). Another 2 samples outside the school were also sampled. Each sampling process was conducted for 3 days. The particle-loaded filters were stored at $4{ }^{\circ} \mathrm{C}$ until analysis.

Duplicate daily foods of the 18 volunteers, which were mostly locally produced, were directly sampled from each family. The food of each child consisted of three meals except soup, which represented the actual amount and type consumed by the child. After the food items in each child's diet were weighed separately, several portions of each food item consumed in one day were combined and blended for freeze-drying and cryopreservation.

\subsubsection{Sample treatment and analysis}

After thoroughly thawing and shaking, whole blood samples (1 mL) were digested with a preparation system (Liu et al., 2009). The water samples were filtered using Whatman no.1 filter membranes before concentration analysis. During pre-treatment of the aerosol samples, the entire piece of filter was digested using an established method (Hu et al., 2012). After being air-dried, ground and sieved, the soil and dust powder samples ( $0.1000 \mathrm{~g}$ each) were then prepared with an acid digestion procedure (Zhang et al., 2010). The freeze-dried food was ground and sieved, and then $0.5000 \mathrm{~g}$ of each child's food was weighed for acid digestion (Li et al., 2006).

All digested solutions were filtered and diluted to appropriate concentrations for instrumental analysis. The concentrations of $\mathrm{Cu}$, $\mathrm{Zn}, \mathrm{Co}, \mathrm{Cr}, \mathrm{Cd}, \mathrm{Pb}, \mathrm{Ni}, \mathrm{Sb}, \mathrm{As}, \mathrm{Se}, \mathrm{Mn}$ and $\mathrm{V}$ in all samples were measured by ICP-MS (Agilent-7500a, Agilent Scientific Technology Ltd., USA) under the optimized conditions (Zhang et al., 2010). A solution containing rhodium and rhenium was added online using a Y-type canal as an internal standard and subjected to concentration measurements. The results were quantified with an empirical calibration curve obtained from the analysis of a multielement calibrations standard material.

Representative reference materials of soil and food, as well as spiked recovery for $\mathrm{PM}_{10}$ were included in each related digestion batch for quality control of the analytical procedure. Reagent and analytical blanks and duplicated processing of each digested batch were analyzed to assess the process efficacy. All chemical reagents in the experiments were guaranteed reagents. The instrument and method detection limits for different metal(loid)s ranged from 2.4 to $45.8 \mathrm{ng} / \mathrm{g}$ (shown in Table S1, supplementary data). The recoveries of the elements were $89-115 \%$. The relative standard 
deviations of the measured elements in parallel treatments were $0.28-2.31 \%$.

\subsection{Exposure assessment via ingestion, dermal contact and inhalation}

According to the Exposure Factors Handbook (US EPA, 1997), the average daily dose (ADD) ( $\mathrm{mg} \mathrm{kg}^{-1} \mathrm{day}^{-1}$ ) of an element via ingestion, inhalation and dermal contact can be estimated using the following equations, respectively:

ADDingest $=\frac{\mathrm{C} \times \text { IngR } \times \mathrm{EF} \times \mathrm{ED}}{\mathrm{BW} \times \mathrm{AT}}$

ADDinhale $=\frac{\mathrm{C} \times \mathrm{t} \times \mathrm{InhR} \times \mathrm{EF} \times \mathrm{ED}}{\mathrm{PEF} \times \mathrm{BW} \times \mathrm{AT}}$

ADDdermal $=\frac{\mathrm{C} \times \mathrm{SA} \times \mathrm{AF} \times \mathrm{ABS} \times \mathrm{ED} \times \mathrm{EF}}{\mathrm{BW} \times \mathrm{AT}}$

where $C$, the concentration of the element $\left(\mathrm{mg} \mathrm{kg}^{-1}\right.$ or $\mu \mathrm{g} \mathrm{m}^{-3}$ and $\left.\mu \mathrm{g} \mathrm{L}^{-1}\right)$; IngR, the ingestion rate ( $\mathrm{mg} \mathrm{day}^{-1}$ or $\mathrm{L} \mathrm{day}^{-1}$ ); InhR, the inhalation rate $\left(\mathrm{m}^{3} \mathrm{day}^{-1}\right)$; $\mathrm{t}$, the exposure time $\left(\mathrm{h} \mathrm{day}^{-1}\right)$; PEF, the inhalation factor for inhalable particles $\left(\mathrm{m}^{3} \mathrm{~kg}^{-1}\right)$; SA, surface area of the skin exposed to pollutants $\left(\mathrm{cm}^{2}\right)$; $\mathrm{AF}$, the skin adherence factor $\left(\mathrm{mg}\left(\mathrm{cm}^{2} \mathrm{~h}\right)^{-1}\right)$; ABS, the dermal absorption factor; $\mathrm{EF}$, exposure frequency (days year $^{-1}$ ); ED, exposure duration (year); $\mathrm{BW}$, body weight $(\mathrm{kg})$; AT, average time (days). The IngR of the children's drinking water and their BW were obtained through the questionnaire. The IngR of consumed food was obtained by weighting of the duplicate food. The other exposure parameters, such as IngRs of the soil/dust were obtained from the literature (Duan, 2012; Duan et al., 2011; US EPA, 1997; US EPA, 2002; Zheng et al., 2010), as shown in Table S2. The penetration coefficient factors for human water exposure by dermal contact are listed in Table S3.

\subsection{Risk calculation}

\subsubsection{Non-carcinogenic risk}

The HQ for children during a lifetime can be calculated by dividing the ADD from each exposure route by a specific reference dose (RfD). The HQ is defined as follows (US EPA, 2011a):

$\mathrm{HQ}=\frac{\mathrm{ADD}}{\mathrm{RfD}}$ where RfD is the estimated maximum permissible risk on humans through daily exposure. If $\mathrm{HQ} \leq 1$, adverse health effects would be unlikely experienced, whereas potential non-carcinogenic effects would occur when HQ $>1$ (Al-Saleh et al., 1999).

To assess the overall potential non-carcinogenic effects posed by many chemicals (e.g., $i$ ), the HQ values of all chemicals were summed (assuming additive effects) and expressed as a HI (US EPA, 1986):

$\mathrm{HI}=\sum_{1}^{\mathrm{i}} \mathrm{HQ}$

The total exposure hazard index (HIt) was used to reflect the non-cancer risks through different pathways and expressed as follows (US EPA, 2011a):

HIt $=\sum_{1}^{\mathrm{i}} \mathrm{HI}($ Exposure pathway 1$)$

If $\mathrm{HIt} \leq 1$, chronic risks are assumed to unlikely happen, whereas non-cancer risks are likely to occur in case HIt $>1$, an analysis segregating the contaminants and separating the HIt would be cogent.

\subsubsection{Carcinogenic risk}

The ILCR of children caused by potential carcinogen exposure over a lifetime was calculated according to the following equation (US EPA, 2011a):

$\mathrm{ILCR}=\mathrm{ADD} \times \mathrm{SF}$

The SF (cancer slope factor) is shown in Table S3. If multiple carcinogenic contaminants are present, the cancer risks from all carcinogen and exposure routes are summed (assuming additive effects). Risks in the range of $1.0 \times 10^{-6}$ to $1.0 \times 10^{-4}$ are acceptable. $\mathrm{Cr}, \mathrm{Cd}, \mathrm{As}, \mathrm{Ni}$ and $\mathrm{Co}$ were treated as potential carcinogenic contaminants, whereas others were regarded as non-carcinogenic elements, based on the order of classification group defined by the International Agency for Research on Cancer (IARC , 2011). The exposure factors such as RfD are listed in Table S3 (US EPA, 2011b).

\subsection{Statistical analysis}

The concentrations of each heavy metal and metalloid are presented as medians and inter-quartile ranges. The correlation coefficients, $r$, between the contents of heavy metal(loid)s in different media were calculated by the Spearman's method. The statistical analysis was conducted using SPSS 20.0 with a significance level of 0.05 for two-tailed testing.

Table 1

The concentrations of heavy metals and metalloids in environmental media.

\begin{tabular}{|c|c|c|c|c|c|c|c|c|c|c|c|c|c|}
\hline Contaminant & Value & $\mathrm{Pb}$ & $\mathrm{Cr}$ & Mn & Co & $\mathrm{Ni}$ & $\mathrm{Cu}$ & $\mathrm{Zn}$ & $\mathrm{Cd}$ & V & As & Se & $\mathrm{Sb}$ \\
\hline \multirow[t]{3}{*}{ Soil mg kg ${ }^{-1}$} & Median & 96.52 & 107.77 & 1127.13 & 15.21 & 48.86 & 62.07 & 186.09 & 0.71 & 206.53 & 348.24 & 243.86 & 12.64 \\
\hline & $25 \%$ & 81.84 & 48.98 & 662.68 & 12.29 & 40.02 & 55.11 & 147.43 & 0.41 & 128.66 & 170.35 & 217.82 & 5.20 \\
\hline & $75 \%$ & 160.88 & 138.45 & 2052.54 & 19.97 & 67.11 & 76.17 & 226.50 & 1.05 & 234.82 & 967.75 & 289.71 & 35.18 \\
\hline \multirow[t]{3}{*}{ Dust $\mathrm{mg} \mathrm{kg}^{-1}$} & Median & 105.95 & 60.06 & 835.35 & 7.43 & 1.09 & 102.83 & 285.40 & 6.42 & 25.84 & 486.80 & 210.27 & 40.97 \\
\hline & $25 \%$ & 37.28 & 34.96 & 481.62 & 5.31 & 0.57 & 61.17 & 408.65 & 4.08 & 20.05 & 150.32 & 160.98 & 19.83 \\
\hline & $75 \%$ & 203.35 & 111.11 & 1190.67 & 8.94 & 1.79 & 124.21 & 598.50 & 10.87 & 38.59 & 729.86 & 250.57 & 90.13 \\
\hline \multirow[t]{3}{*}{ Ambient air $\mu \mathrm{g} \mathrm{m}^{-3}$} & Median & 0.21 & 0.21 & 0.23 & 0.01 & 0.03 & 0.16 & 0.28 & 0.04 & 0.01 & 0.21 & 0.03 & 0.14 \\
\hline & $25 \%$ & 0.17 & 0.14 & 0.20 & 0.00 & 0.02 & 0.16 & 0.17 & 0.03 & 0.01 & 0.12 & 0.01 & 0.12 \\
\hline & $75 \%$ & 0.28 & 0.41 & 0.27 & 0.01 & 0.07 & 0.19 & 0.32 & 0.05 & 0.03 & 0.26 & 0.05 & 0.15 \\
\hline \multirow[t]{3}{*}{ Drinking water $\mu \mathrm{g} \mathrm{L}^{-1}$} & Median & 0.67 & 7.01 & 2.60 & 0.21 & 1.73 & 1.72 & 193.00 & 0.04 & 3.20 & 0.11 & 0.35 & 1.05 \\
\hline & $25 \%$ & 0.59 & 6.42 & 2.19 & 0.18 & 1.53 & 1.51 & 184.52 & 0.03 & 2.73 & 0.07 & 0.27 & 0.94 \\
\hline & $75 \%$ & 0.76 & 7.39 & 3.08 & 0.29 & 1.98 & 2.05 & 204.15 & 0.04 & 3.76 & 0.11 & 0.41 & 1.14 \\
\hline \multirow[t]{3}{*}{ Duplicate food $\mathrm{mg} \mathrm{kg}^{-1}$} & Median & 0.52 & 0.45 & 2.96 & 0.65 & 0.55 & 26.24 & 22.51 & 0.07 & 0.15 & 0.13 & 0.12 & 0.03 \\
\hline & $25 \%$ & 0.23 & 0.05 & 1.57 & 0.09 & 0.27 & 2.09 & 2.87 & 0.02 & 0.12 & 0.02 & 0.02 & 0.01 \\
\hline & $75 \%$ & 1.33 & 1.06 & 3.64 & 1.23 & 0.73 & 41.99 & 28.11 & 0.16 & 0.38 & 0.19 & 0.17 & 0.04 \\
\hline
\end{tabular}




\section{Results and discussion}

\subsection{Levels of heavy metal and metalloid in the environment}

The heavy metal(loid) contents in environmental media are listed in Table 1. The mean values of $\mathrm{Cu}, \mathrm{Ni}, \mathrm{Pb}, \mathrm{Cd}, \mathrm{As}, \mathrm{Cr}$ and $\mathrm{Zn}$ in soil were 1.8-24.9 times higher than the related natural background levels in the soils of Hunan province (Pan and Yang, 1998). This result agreed with other studies, and they demonstrated that heavy pollution of $\mathrm{As}, \mathrm{Pb}, \mathrm{Cd}, \mathrm{Cr}$, etc., in a large part of soils in Hunan was attributed to frequent ore-related activities (Fang et al., 2006; Guo and Zhu, 2004; Liu, 2011). Furthermore, as recycled scrap metal batteries and ores are the main raw materials, lots of heavy metal(loid)s are released into the environment during the lead-acid battery production (Cherry et al., 2009). For instance, it was estimated that $40 \%$ of the total $\mathrm{Pb}$ could be emitted from this source (Mao et al., 2008). Therefore, in addition to mining and smelting activities, the pollution of $\mathrm{Pb}, \mathrm{Cr}$ and As, etc., could be mainly attributed to the lead-acid battery plant, since there were no other large industrial activities around the area.

In comparison, it appears that the heavy metal(loid)s pollution in indoor dust was even more serious. The levels of $\mathrm{As}, \mathrm{Cd}, \mathrm{Cu}, \mathrm{Zn}$ and $\mathrm{Pb}$ in dust samples were $34.8,64.3,4.6,3.9$ and 4.1 times, respectively, higher than the related natural background levels (Pan and Yang, 1998). Based on bivariate correlation analysis, although significant positive correlations were found in $\mathrm{Cr}, \mathrm{Cu}$ and $\mathrm{Pb}$ between indoor dust and courtyard soil, $\mathrm{Cd}$ and As concentrations in indoor dust were negatively correlated with those in courtyard soil (Spearman $r=-0.720$ and $-0.601, \mathrm{p}<0.05$, respectively), respectively. These results illustrated that indoor dust had complex pollution sources for different heavy metal(loid)s, and $\mathrm{Cr}$, $\mathrm{Cu}$ and $\mathrm{Pb}$ levels in indoor dust may be partly attributed to the courtyard soil. Whereas, $\mathrm{Cd}$ and As pollution in indoor dust may did not originate from the courtyard soil but could be partly attributed to atmospheric deposition (Han et al., 2006; Zheng et al., 2010) and longterm accumulation from various pollution sources (Banerjee, 2003; Leung et al., 2008).

For indoor $\mathrm{PM}_{10}$, the results showed that $\mathrm{Pb}, \mathrm{Cr}, \mathrm{Mn}, \mathrm{Zn}$ and $\mathrm{As}$ were the most abundant pollutants, which was similar to the results of previous studies (Hu et al., 2012). Although Pb concentration in $\mathrm{PM}_{10}$ in this study was within the thresholds (1.0 and $0.5 \mu \mathrm{g} \mathrm{m}^{-3}$ as seasonal and annual thresholds, respectively), the contents of $\mathrm{Cu}, \mathrm{Pb}, \mathrm{Zn}$, particularly $\mathrm{As}$ in $\mathrm{PM}_{10}$ were generally higher than those at other counterparts (Lopez et al., 2005; Wang et al., 2013). The observation that many As and nonferrous mining operations contributing to environmental heavy metal(loid) pollution in Hunan may explain this result (Guo and Zhu, 2004; Liu, 2011). Moreover, compared to the thresholds regulated by WHO guidelines with maximum values of 5 and $150 \mathrm{ng} \mathrm{m}^{-3}$ for $\mathrm{Cd}$ and $\mathrm{Mn}$, respectively, the concentrations of $\mathrm{Cd}$ and Mn were respectively 8 and 1.5 times higher than the related thresholds. Additionally, the contents of As and $\mathrm{Sb}$ in $\mathrm{PM}_{10}$ were respectively positively correlated to those in dust (Spearman $r=0.674$ and 0.519, $\mathrm{p}<0.05$, respectively), illustrating that $\mathrm{As}$ and $\mathrm{Sb}$ in $\mathrm{PM}_{10}$ and dust may have similar pollution sources, respectively.

The tap water in this study was considered safe for local people.

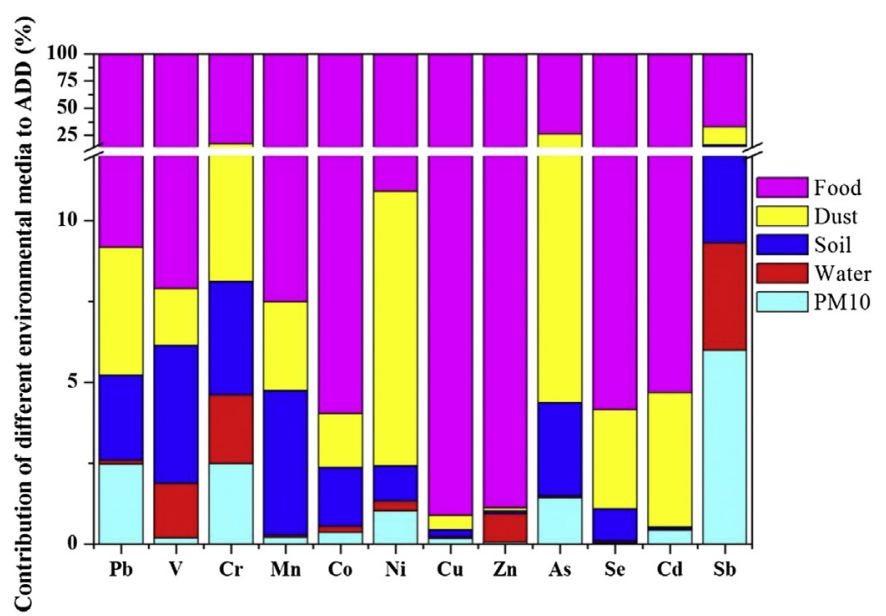

Fig. 1. The contribution of $\mathrm{PM}_{10}$, drinking water, soil/dust and food via inhalation, ingestion and dermal contact to the average daily exposure dose of children exposure to heavy metal(loid)s.

For the daily duplicate food, $\mathrm{Pb}$ was the most prevalent pollutant comparing to the related thresholds in the National Food Quality standard (0.05-1.0 $\mathrm{mg} \mathrm{kg}^{-1}$ for different food species), which was 1.7-5.9 times higher than the thresholds. Most heavy metal(loid)s in food were correlated with others in concentration (Table S4), indicating the similar pollution source. Notably, $\mathrm{Cr}, \mathrm{Cu}, \mathrm{As}$ and $\mathrm{Pb}$ contents in food were significantly correlated with those in soil. It is speculated that soil could be an important contributor to food pollution by $\mathrm{Pb}, \mathrm{As}, \mathrm{Cr}$ and $\mathrm{Cu}$, as previous studies found that the accumulation of heavy metals in crops was positively correlated with the contents of heavy metals in soil (Xu et al., 2008).

\subsection{Contents of heavy metals and metalloids in children's blood}

Blood is usually regarded as the most representative matrix for the bio-monitoring of metal exposure in environmental toxicology (Batariova et al., 2006; Gil and Pla, 2001). The contents of heavy metal(loid)s in children's blood are shown in Table 2. In agreement with previous studies (Cao et al., 2014; Wu et al., 2011b), a negative correlation was found between $\mathrm{Pb}$ and $\mathrm{Zn}$, after controlling for gender and age. This could be attributed to the fact that $\mathrm{Zn}$ plays an important role in $\mathrm{Pb}$ metabolism (Jamieson et al., 2006). However, it is reported that $\mathrm{Zn}$ supplementation does not reduce blood lead level (BLL) independently of Zn nutritional status (Roth et al., 2010).

BLL is widely used as the most reliable indicator to evaluate $\mathrm{Pb}$ exposure (Barbosa et al., 2005; Coon et al., 2006; He et al., 2009). The children in our study showed an elevated BLL $\left(12.52 \mu \mathrm{g} \mathrm{dL}^{-1}\right)$, higher than the defined diagnostic criteria $\left(10 \mu \mathrm{g} \mathrm{dL}^{-1}\right)$ (CDC , 1991). Actually, children living around the battery area suffered from a severe lead pollution, based on the new updated criteria of $5.00 \mu \mathrm{g} \mathrm{dL}^{-1}$ (http://www.cdc.gov/nech/lead/ACCLPP/blood_lead_ levels.htm). Moreover, the prevalence rate of elevated BLLs was $59.38 \%$, which was much higher than the national rate $(23.90 \%$ ) (He et al., 2009). It concluded that the studied children were being

Table 2

The contents of heavy metals and metalloids in children's blood $\left(\mu \mathrm{g} \mathrm{dL}^{-1}\right)$.

\begin{tabular}{|c|c|c|c|c|c|c|c|c|c|c|c|c|c|}
\hline Content & Value & $\mathrm{Pb}$ & $\mathrm{Cr}$ & $\mathrm{Mn}$ & Co & $\mathrm{Ni}$ & $\mathrm{Cu}$ & $\mathrm{Zn}$ & $\mathrm{Cd}$ & V & As & Se & $\mathrm{Sb}$ \\
\hline \multirow[t]{4}{*}{ Blood $\mu \mathrm{g} \mathrm{dL}^{-1}$} & $25 \%$ & 5.93 & 1.81 & 2.01 & 0.11 & 0.48 & 9.28 & 38.17 & 0.06 & 0.41 & 0.32 & 13.93 & 1.49 \\
\hline & Mean & 12.45 & 4.23 & 4.03 & 0.79 & 8.86 & 12.17 & 44.58 & 0.23 & 0.88 & 1.46 & 18.81 & 3.49 \\
\hline & Median & 12.52 & 3.46 & 3.44 & 0.36 & 8.79 & 11.49 & 44.66 & 0.19 & 0.89 & 0.87 & 19.10 & 2.61 \\
\hline & $75 \%$ & 17.59 & 5.01 & 5.42 & 1.07 & 27.75 & 14.34 & 50.57 & 0.34 & 1.12 & 1.79 & 22.53 & 4.71 \\
\hline
\end{tabular}


Table 3

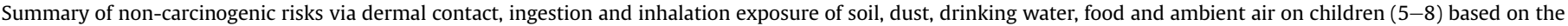
total element concentrations and field measurements of the exposure factors at the 5th, median and 95th percentiles.

\begin{tabular}{|c|c|c|c|c|c|c|c|c|c|c|c|c|}
\hline \multirow[t]{2}{*}{ Metal(loid)s } & \multicolumn{4}{|l|}{$5 \%$} & \multicolumn{4}{|l|}{ Median } & \multicolumn{4}{|l|}{$95 \%$} \\
\hline & $\mathrm{HI}_{\text {ing }}$ & $\mathrm{HI}_{\text {inh }}$ & $\mathrm{HI}_{\text {dermal }}$ & HIt & $\mathrm{HI}_{\text {ing }}$ & $\mathrm{HI}_{\text {inh }}$ & $\mathrm{HI}_{\text {dermal }}$ & HIt & $\mathrm{HI}_{\text {ing }}$ & $\mathrm{HI}_{\text {inh }}$ & $\mathrm{HI}_{\text {dermal }}$ & HIt \\
\hline $\mathrm{Pb}$ & $4.25 \mathrm{E}+00$ & $6.20 \mathrm{E}-02$ & 5.93E-05 & $4.33 E+00$ & $7.30 \mathrm{E}+00$ & 7.90E-02 & 7.27E-05 & $7.37 \mathrm{E}+00$ & $1.49 \mathrm{E}+00$ & $9.55 \mathrm{E}-02$ & $8.86 \mathrm{E}-05$ & $1.50 \mathrm{E}+01$ \\
\hline V & $2.49 \mathrm{E}-01$ & $4.24 \mathrm{E}-01$ & 7.57E-06 & $6.88 \mathrm{E}-01$ & $4.20 \mathrm{E}-01$ & $5.04 \mathrm{E}-01$ & $9.27 \mathrm{E}-06$ & $9.02 \mathrm{E}-01$ & $8.35 \mathrm{E}-01$ & $6.06 \mathrm{E}-01$ & $1.09 \mathrm{E}-05$ & $1.39 \mathrm{E}+00$ \\
\hline $\mathrm{Cr}$ & $1.33 E+00$ & $4.75 E+00$ & $1.87 \mathrm{E}-03$ & $6.10 E+00$ & $2.15 E+00$ & $5.72 E+00$ & $2.30 \mathrm{E}-03$ & $7.82 E+00$ & $4.20 \mathrm{E}+00$ & $7.04 \mathrm{E}+00$ & $2.80 \mathrm{E}-03$ & $1.06 \mathrm{E}+01$ \\
\hline Mn & $2.89 \mathrm{E}-01$ & 8.57E +00 & $2.68 \mathrm{E}-05$ & $9.04 E+00$ & $4.94 \mathrm{E}-01$ & $1.01 E+01$ & $3.29 \mathrm{E}-05$ & $1.07 E+01$ & $1.01 E+00$ & $1.30 \mathrm{E}+01$ & 4.00E-05 & $1.36 \mathrm{E}+01$ \\
\hline Co & $4.08 \mathrm{E}-01$ & $2.27 \mathrm{E}-01$ & $1.63 \mathrm{E}-03$ & 6.74E-01 & 7.10E-01 & $2.88 \mathrm{E}-01$ & $1.99 \mathrm{E}-03$ & $9.65 \mathrm{E}-01$ & $1.46 E+00$ & 4.07E-01 & $2.43 \mathrm{E}-03$ & $1.79 \mathrm{E}+00$ \\
\hline $\mathrm{Ni}$ & $3.45 \mathrm{E}-01$ & 4.67E-03 & $1.73 \mathrm{E}-04$ & $3.51 \mathrm{E}-01$ & $5.65 \mathrm{E}-01$ & $5.88 \mathrm{E}-03$ & $2.11 \mathrm{E}-04$ & $5.70 \mathrm{E}-01$ & $1.15 E+00$ & 8.17E-03 & 2.57E-04 & $1.15 E+00$ \\
\hline $\mathrm{Cu}$ & $8.62 \mathrm{E}-01$ & 2.10E-03 & 2.19E-06 & $8.65 \mathrm{E}-01$ & $1.58 E+00$ & 2.64E-03 & 2.69E-06 & $1.59 \mathrm{E}+00$ & $3.30 \mathrm{E}+00$ & $3.66 \mathrm{E}-03$ & $3.27 \mathrm{E}-06$ & $3.31 \mathrm{E}+00$ \\
\hline $\mathrm{Zn}$ & $7.98 \mathrm{E}-01$ & $5.26 \mathrm{E}-04$ & $2.06 \mathrm{E}-06$ & 7.99E-01 & $1.46 \mathrm{E}+00$ & $6.45 \mathrm{E}-04$ & $2.53 \mathrm{E}-06$ & $1.46 E+00$ & $3.05 E+00$ & $7.85 \mathrm{E}-04$ & $3.08 \mathrm{E}-06$ & $3.05 E+00$ \\
\hline As & 4.67E +00 & $1.59 \mathrm{E}-01$ & $1.01 \mathrm{E}-03$ & $4.83 E+00$ & $6.37 E+00$ & $2.05 \mathrm{E}-01$ & $1.24 \mathrm{E}-03$ & $6.58 E+00$ & $1.03 E+01$ & $2.48 \mathrm{E}-01$ & $1.51 \mathrm{E}-03$ & $1.05 E+01$ \\
\hline Se & $1.69 \mathrm{E}+00$ & 6.19E-02 & $9.90 \mathrm{E}-06$ & $1.77 E+00$ & $2.99 \mathrm{E}+00$ & $7.55 \mathrm{E}-02$ & $1.22 \mathrm{E}-05$ & $3.05 E+00$ & $6.16 E+00$ & $9.26 \mathrm{E}-02$ & $1.48 \mathrm{E}-05$ & $6.25 E+00$ \\
\hline $\mathrm{Cd}$ & $1.42 \mathrm{E}+00$ & $1.51 \mathrm{E}-01$ & $3.38 \mathrm{E}-05$ & $1.62 E+00$ & $2.51 E+00$ & $1.98 \mathrm{E}-01$ & 4.15E-05 & $2.67 E+00$ & $5.17 \mathrm{E}+00$ & $2.39 \mathrm{E}-01$ & $5.05 \mathrm{E}-05$ & $5.36 \mathrm{E}+00$ \\
\hline $\mathrm{Sb}$ & $1.00 \mathrm{E}+00$ & $1.88 \mathrm{E}-01$ & $3.10 \mathrm{E}-04$ & $1.18 E+00$ & $1.50 \mathrm{E}+00$ & $2.72 \mathrm{E}-01$ & $3.81 \mathrm{E}-04$ & $1.75 E+00$ & $2.70 \mathrm{E}+00$ & $3.28 \mathrm{E}-01$ & 4.63E-04 & $3.02 E+00$ \\
\hline Total & $1.73 E+01$ & $1.46 \mathrm{E}+01$ & 5.13E-03 & $3.22 \mathrm{E}+01$ & $2.80 \mathrm{E}+01$ & $1.75 E+01$ & $6.30 \mathrm{E}-03$ & $4.54 \mathrm{E}+01$ & $4.08 \mathrm{E}+01$ & $2.21 E+01$ & 7.67E-03 & $7.50 \mathrm{E}+01$ \\
\hline
\end{tabular}

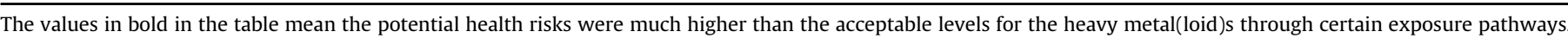

exposed to a severe risk of $\mathrm{Pb}$ poisoning because of the heavier environmental pollution, due to the lead-acid battery manufacturing and ore-related activities. On the basis of bivariate correlation analysis, significant positive correlation of $\mathrm{Pb}$ in food and children's blood was found (Spearman $r=0.509, \mathrm{p}<0.05$ ), indicating food ingestion would be a potential pathway for children's lead exposure. Furthermore, although $\mathrm{Pb}$ concentration in children's blood didn't show significant correlation with that in indoor dust, PM or soil, the children aged from 5 to 8 years in our study, were likely to perform frequent hand-to-mouth activities (Wu et al., 2011), which would lead to certain potential risks for children's lead exposure. In addition, the studied children with a height of $102-121 \mathrm{~cm}$ mostly living in the bungalow, were likely to inhale the heaviest lead-contaminated zone in the air, which is 75-100 cm above the ground (Dong et al., 2001; Wang and Zhang, 2006). Moreover, the children's BLLs in this study, were much higher than those of children living around a coking plant (Cao et al., 2014), an traffic area (Huang et al., 2012) and a smelting facility (Soto-Jimenez and Flegal, 2011). The variance can be explained by the aforementioned factors related to the children, and the heavier contamination status in our site, as environmental lead pollution was reported to be a factor in the children's elevated BLLs (Wang and Zhang, 2006).

\subsection{Daily exposure doses of heavy metals and metalloids}

Aerosol particles, dust/soil, food and drinking water are the main pathways for human exposure to contaminants (Di;azSomoano et al., 2009; US EPA, 1997). The contribution of each

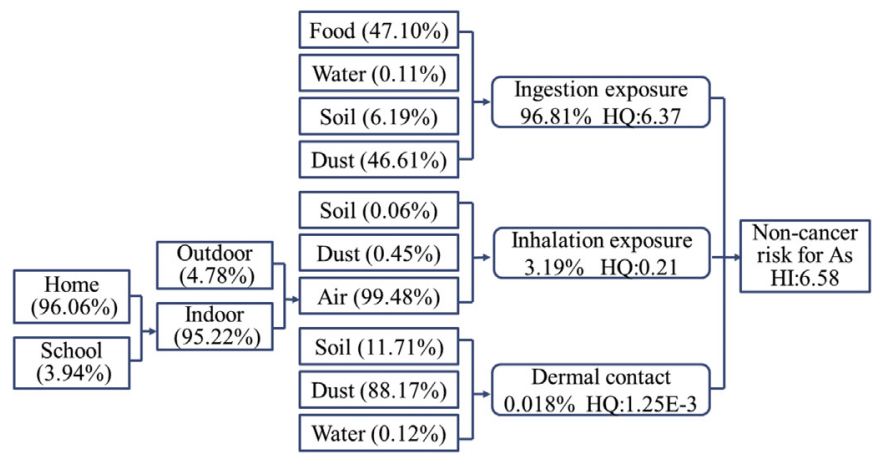

Fig. 2. Multi-pathway analysis of HQ (As). Each pathway's contribution to the total As exposure of the local children. exposure route to children's ADD of heavy metal(loid)s was shown in Fig. 1. The results illustrated that the ADD of children was largely attributed to food ingestion for most heavy metal(loid)s, especially for $\mathrm{Co}, \mathrm{Cu}, \mathrm{Zn}$, Se and Cd, which accounted for 95.97, 99.13, 98.88, 95.85 and $95.32 \%$, respectively. The result was in accordance with the previous study conducted near a coking area, which indicated that food ingestion was the largest contributor to the total ADD of metal(loid)s exposure (Cao et al., 2014). However, for As, dust ingestion was another large contributor to the ADD, which accounted for $21.90 \%$. This could be mainly attributed to the relatively higher As level in the dust and implied that dust could pose a higher risk to the local children via the ingestion pathway. For Sb, $\mathrm{PM}_{10}$ inhalation exposure was another contributing pathway, accounting for $5.98 \%$.

\subsection{Risk characteristics}

\subsubsection{Non-cancer risks}

The HI and HIt of various heavy metal(loid)s through different exposure pathways are shown at the 5th, median and 95th percentiles in Table 3. The HIt of heavy metals and metalloids in children decreased in the order of $\mathrm{Mn}>\mathrm{Cr}>\mathrm{Pb}>\mathrm{As}>$ $\mathrm{Se}>\mathrm{Cd}>\mathrm{Sb}>\mathrm{Cu}>\mathrm{Zn}>\mathrm{Co}>\mathrm{V}>\mathrm{Ni}$, indicating that $\mathrm{Mn}, \mathrm{Cr}$, $\mathrm{Pb}$ and As were potentially highly deleterious to children's health. As mentioned previously, the lead-acid battery plant was the sole enterprise in the study site, $\mathrm{Pb}, \mathrm{Cr}$, As, et al., would be mainly from the manufacturing process in the battery plant and would pose heavy health risks to the local children. However, further research

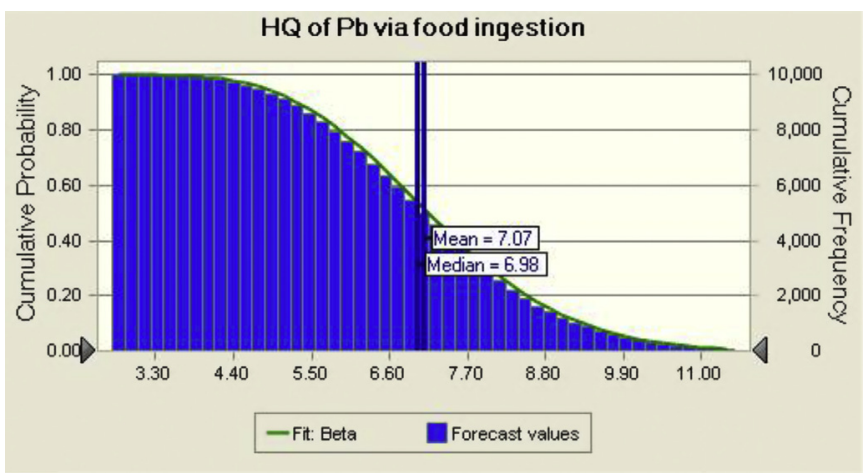

Fig. 3. Cumulative probability distribution of the $\mathrm{HQ}$ of $\mathrm{Pb}$ from food ingestion. The health risk was evaluated by means of a Monte Carlo simulation based on Crystal ball soft for 10000 iterations. 
Table 4

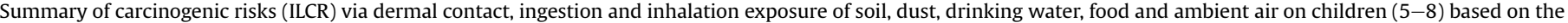
total element concentrations and field measurements of the exposure factors at the 5th, median and 95th percentiles.

\begin{tabular}{|c|c|c|c|c|c|c|c|c|c|c|c|c|}
\hline \multirow[t]{2}{*}{ Metal(loid)s } & \multicolumn{4}{|l|}{$5 \%$} & \multicolumn{4}{|l|}{ Median } & \multicolumn{4}{|l|}{$95 \%$} \\
\hline & Ingestion & Inhalation & Dermal & Sum & Ingestion & Inhalation & Dermal & Sum & Ingestion & Inhalation & Dermal & Sum \\
\hline $\mathrm{Cr}$ & 1.35E-02 & $1.05 \mathrm{E}-04$ & 6.97E-07 & $\sum=1.35 \mathrm{E}-02$ & 2.44E-02 & $1.14 \mathrm{E}-04$ & $8.25 \mathrm{E}-07$ & $\sum=2.45 \mathrm{E}-02$ & 4.99E-02 & $1.23 \mathrm{E}-04$ & $1.03 \mathrm{E}-06$ & $\sum=5.00 \mathrm{E}-02$ \\
\hline Co & NA & $5.76 \mathrm{E}-06$ & NA & $\sum=5.76 \mathrm{E}-06$ & NA & 7.27E-06 & NA & $\sum=7.27 \mathrm{E}-06$ & NA & $1.04 \mathrm{E}-05$ & NA & $\sum=1.04 \mathrm{E}-05$ \\
\hline $\mathrm{Ni}$ & $5.67 \mathrm{E}-04$ & 7.47E-06 & 4.17E-09 & $\sum=5.74 \mathrm{E}-04$ & 1.00E-03 & $9.54 \mathrm{E}-06$ & 4.94E-09 & $\sum=1.01 E-03$ & 2.00E-03 & $1.28 \mathrm{E}-05$ & $6.20 \mathrm{E}-09$ & $\sum=2.00 \mathrm{E}-03$ \\
\hline As & $2.38 E-03$ & $6.70 \mathrm{E}-05$ & 2.39E-08 & $\sum=2.45 \mathrm{E}-03$ & 4.45E-03 & $8.56 \mathrm{E}-05$ & $2.84 \mathrm{E}-08$ & $\sum=4.54 \mathrm{E}-03$ & 9.05E-03 & $1.02 \mathrm{E}-04$ & 3.57E-08 & $\sum=$ 9.15E-03 \\
\hline $\mathrm{Cd}$ & NA & $5.08 \mathrm{E}-06$ & NA & $\sum=5.08 \mathrm{E}-06$ & NA & $6.52 \mathrm{E}-06$ & NA & $\sum=6.52 \mathrm{E}-06$ & NA & $7.89 \mathrm{E}-06$ & NA & $\sum=7.89 \mathrm{E}-06$ \\
\hline Total & 1.64E-02 & $1.90 \mathrm{E}-04$ & $7.25 \mathrm{E}-07$ & $\sum=1.67 \mathrm{E}-02$ & 2.99E-02 & $2.23 \mathrm{E}-04$ & $8.58 \mathrm{E}-07$ & $\sum=3.01 E-02$ & 6.10E-02 & $2.56 \mathrm{E}-04$ & $1.08 \mathrm{E}-06$ & $\sum=6.13 E-02$ \\
\hline
\end{tabular}

NA-not applicable.

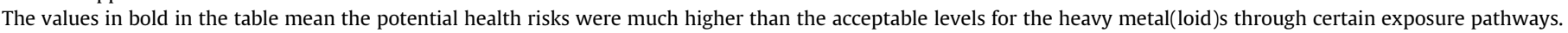

is needed to identify the extent to what the battery plant increased the risks of exposure to heavy metal(loid)s. Additionally, it also indicated that the risk from dermal contact would be negligible. While, the ingestion appeared to be the predominant contributor to the non-cancer risk for most heavy metal(loid)s, particularly for $\mathrm{Pb}$, $\mathrm{Cr}, \mathrm{As}, \mathrm{Se}, \mathrm{Cd}$ and $\mathrm{Sb}$. Furthermore, the inhalation exposure could be another important contributor to local children's health effects due to the non-cancer risks from $\mathrm{Mn}$ and $\mathrm{Cr}$, as their calculated HQs via inhalation exposure exceeded 1 even at the 5th percentile, respectively.

Ingestion exposure was divided into different routes to identify the main exposure pathways, as shown in Table S5. It indicated that the non-cancer risks via water and soil were negligible. However, it further illustrated that $\mathrm{Pb}, \mathrm{As}$, Se and $\mathrm{Cd}$ exposure through food ingestion contributed greatly to the total $\mathrm{HQ}$ followed by As exposure via dust ingestion, with $\mathrm{HQ}$ values of 3.70, 1.61, 1.55, 1.30 and 2.56 at the 5 th percentile, respectively. These results confirmed the previous studies that heavier pollution of $\mathrm{As}, \mathrm{Pb}$, etc., would result in a high health risk to the local children (Chen et al., 2012; Liu et al., 2005). The HIs via inhalation exposure through $\mathrm{PM}_{10}$, soil and dust illustrated that $\mathrm{PM}_{10}$ inhalation was the predominant exposure pathway (shown in Table S6). Actually, the HQs for most heavy metal(loid)s via $\mathrm{PM}_{10}$ inhalation were $1.0 \times 10^{2}$ to $1.0 \times 10^{5}$ times higher than those of soil and dust routes via inhalation exposure. In particular, the $\mathrm{HQs}$ for $\mathrm{Cr}$ and $\mathrm{Mn}$ via $\mathrm{PM}_{10}$ inhalation were 4.75 and 8.48 at the 5th percentile, respectively, indicating that the higher $\mathrm{Cr}$ and $\mathrm{Mn}$ contents in $\mathrm{PM}_{10}$ would pose a risk of harmful effect to the local children, which had also been found in a previous study (Cao et al., 2014).

In this study, the mean combined HIt for all heavy metal(loid)s were 45.4 , indicating a higher potential non-carcinogenic risk to the local children when compared to the previous results (Cao et al., 2014; Qu et al., 2012). The main reasons for the difference between the studies would be that the heavier site-specific contaminants played an important role in this present study, besides the consideration of more toxic metal(loid)s in the integrated exposure assessment. Based on the health risk assessment, we determined that the ingestion exposure via $\mathrm{Pb}, \mathrm{Cr}, \mathrm{As}, \mathrm{Se}, \mathrm{Cd}$ and $\mathrm{Sb}$ and inhalation exposure via $\mathrm{Cr}$ and $\mathrm{Mn}$ were the major contributors to the non-cancer risk, and that adverse health effects on children via dermal contact could be negligible. Using As, $\mathrm{Cd}$ and $\mathrm{Cr}$ as examples, each pathway's contribution to the children's noncarcinogenic risk were calculated. As shown in Fig. 2, the ingestion exposure was responsible for the As non-carcinogenic risk. The intake of food and dust contributed nearly equally to the total ingestion exposure, accounting for $47.10 \%$ and $46.64 \%$, respectively. While, the health risks through inhalation and dermal contact were considered acceptable. Among inhalation exposure risks, the indoor air was the larger contributor, which was mainly attributed to the home interior exposure. The time spent at home and the contaminant status of household air, would be the key determinants of the higher exposure level at home. This result was consistent with the previous study (Cao et al., 2014), which illustrated that home indoor air would pose greater risk to children compared to school air exposure. The local children's exposure to $\mathrm{Cd}$ occurred largely through food ingestion, while inhalation exposure and dermal contact were regarded to be less harmful (Figure S1). For Cr exposure (Figure S2), ingestion and inhalation exposure contributed $28.57 \%$ and $71.43 \%$ to the total $\mathrm{HI}$, respectively. In contrast to As and Cd exposure, the outdoor and indoor air contributed almost equally to the air inhalation of $\mathrm{Cr}$, accounting for $51.07 \%$ and $48.93 \%$, respectively. This could be mainly attributed to the finding that the indoor air was less polluted by $\mathrm{Cr}$ compared with that in outdoor air.

To assess the uncertainties associated with the exposure factors, the cumulative probability distribution of the calculated $\mathrm{HQ}$ of $\mathrm{Pb}$ exposure via food ingestion was depicted as an example using a Monte Carlo simulation in Fig. 3. The mean and median values of the HQ were 7.07 and 6.98 , respectively, which were close to the calculated value (6.69) based on the health risk assessment model from USEPA. This suggested that there was probably little bias in the risk evaluation in this study and there were higher potential non-cancer effects to the local children from many exposure routes, particularly from food ingestion.

\subsubsection{Cancer risks}

According to the USEPA, one to one hundred in a million chance of additional human cancer over a 70-year lifetime $\left(\right.$ ILCR $\left.=1.0 \times 10^{-6} \sim 1.0 \times 10^{-4}\right)$ is regarded as an acceptable or inconsequential risk (US EPA, 2011b). From Table 4, the total ILCR via dermal contact and inhalation exposure was slightly higher than the maximum acceptable level $\left(1.0 \times 10^{-4}\right)$ at the 95 th percentile. We then concluded that there was no serious or high priority for focusing on the cancer risk to local children through these two exposure pathways. However, the ILCR from $\mathrm{Cr}$, As and $\mathrm{Ni}$ ingestion pathway was larger than the maximum acceptable level $\left(1.0 \times 10^{-4}\right)$ even at the 5th percentile. It demonstrated that the high potential carcinogenic risks to the local children were mainly attributed to $\mathrm{Cr}$, As and $\mathrm{Ni}$ through ingestion exposure pathway. Different to the previous study (Cao et al., 2014), which illustrated that the carcinogenic effect attributable little to As via ingestion exposure but largely from As via inhalation, the present study found the reverse story. The results showed that the ILCR of As via ingestion pathway was 10 times higher than the maximum acceptable level at the 5th percentile, whereas the ILCR via inhalation exposure could be considered acceptable. Taking the ADD and the contents of pollutants into account, we emphasized the importance of effective environmental management to ensure food security.

Furthermore, it's worthy to mention that the total carcinogenic risk from $\mathrm{Cr}$ and As was much higher than $1.0 \times 10^{-4}$, indicating that their cancer effects on local children cannot be negligible. Compared to As, the potential cancer risks via ingestion exposure 
were largely attributed to $\mathrm{Cr}$, which accounted for approximately $82 \%$, implying that $\mathrm{Cr}$ and As exposure were detrimental to the local children both from ingestion and inhalation exposure.

\subsection{Uncertainly analysis}

The inherent uncertainty in health risk assessment inevitably affected the results in our study. Firstly, the bioavailable concentrations of pollutants are more accurate during the human risk assessment (Oomen et al., 2002). Secondly, certain uncertainties during dose-effect simulation experiments may exist in quantitative risk assessment (Xia et al., 2010). Additionally, the variance during the sample analysis and homogeneity could also bring about certain uncertainties (Zeleny et al., 2015). However, animal experiments to quantify the bioavailability of each pollutant in human metabolism are costly and would cause ethical concerns, while in vitro digestion models are not suitable for assessing the inhalation and dermal exposure. Therefore, the non-cancer and cancer risks based on the total pollutant concentrations in this study would be little overestimated.

The contribution from the battery plant through metal(lios)s to the health risks of the local children was unclear, because of the limited questionnaire and field research conducted in/near the plant. However, it encourages further research using other methods to identify the contribution of the battery plant to the local children's health risks. Despite the lack of an absolutely accurate risk assessment, this study scored health effects based on a welldefined investigation on different exposure pathways and various heavy metal(loid)s to the local children in the vicinity of the typical lead-acid battery plant, and filled the information gap in the mainland of China.

\section{Conclusion}

Courtyard soil, indoor dust and duplicate food were heavily contaminated by heavy metal(loid)s. Pb was one of the most abundant elements in children's blood, with an elevated BLL of $12.45 \mu \mathrm{g} \mathrm{dL}^{-1}$. Attributing to the ingestion exposure via $\mathrm{Cr}, \mathrm{Pb}, \mathrm{As}, \mathrm{Se}$ and $\mathrm{Cd}$ in food and inhalation exposure via $\mathrm{Cr}$ and $\mathrm{Mn}$ in $\mathrm{PM}_{10}$, the non-cancer risks to the local children were 3-10 times higher than the acceptable level. The potentially higher cancer risks mainly resulted from $\mathrm{Cr}$, As and $\mathrm{Ni}$ via ingestion exposure pathway. Thus, more attention should be paid to the environmental quality, particularly to the food security, to reduce the health risks of children living in the vicinity of lead-acid battery plant. The study strongly recommended the further investigation to identify the contributions of the battery plant to the health of children living nearby.

\section{Acknowledgment}

The founding of this study was provided by the Ministry of Environmental Protection of China (201109064) and the Open Foundation of State Key Laboratory of Environmental Criteria and Risk Assessment (SKLECRA20130FP05).

\section{Appendix A. Supplementary data}

Supplementary data related to this article can be found at http:// dx.doi.org/10.1016/j.envpol.2015.02.010.

\section{References}

Ahmed, K., Ayana, G., Engidawork, E., 2008. Lead exposure study among worker in lead acid battery repair units of transport sevice enterprise, Addis Ababa, Ethiopia a cross sectional study. J. Occup. Med. Toxicol. 30, 1-8.
Al-Saleh, I., Nester, M., Devol, E., Shinwari, N., Al-Shahria, S., 1999. Determinants of blood lead levels in Saudi Arabian schoolgirls. Int. J. Occup. Environ. Health 5, 107-114.

Banerjee, A.D.K., 2003. Heavy metal levels and solid phase speciation in street dusts of Delhi, India. Environ. Pollut. 123, 95-105.

Barbosa, F.J., Tanus-Santos, J.E., Gerlach, R.F., Parsons, P.J., 2005. A critical review of biomakers used for monitoring human exposure to lead_advantages, limitations, and future needs. Environ. Health Perspect. 113, 1669-1674.

Batariova, A., Spevackova, V., Benes, B., Cejchanova, M., Smid, J., Cerna, M., 2006. Blood and urine levels of $\mathrm{Pb}, \mathrm{Cd}$ and $\mathrm{Hg}$ in the general population of the Czech Republic and proposed reference values. Int. J. Environ. Health 209, 359-366.

Cao, S.Z., Duan, X.L., Zhao, X.G., Ma, J., Dong, T., Huang, N., et al., 2014. Health risks from the exposure of children to $\mathrm{As}$, $\mathrm{Se}, \mathrm{Pb}$ and other heavy metlas near the largest coking plant in China. Sci. Total Environ. 472, 1001-1009.

CDC (Centers for Disease Control), 1991. Preventing Lead Poisoning in Young Children: a Statement by the Centers for Disease Control, October 1991. Centers for Disease Control, Atlanta, GA (United States).

Chen, H.Y., Li, A.J., Finlow, D.E., 2009. The lead and lead-acid battery industries during 2002 and 2007 in China. J. Power Sources 191, 22-27.

Chen, L.G., Xu, Z.C., Liu, M., Huang, Y.M., Fan, R.F., Su, Y.H., et al., 2012. Lead exposure assessment from study near a lead-acid battery factory in China. Sci. Total Environ. 429, 191-198.

Cherry, C.R., Weinert, J.X., Yang, X., 2009. Comparative environmental impacts of electric bikes in China. Transp. Res. Part D 14, 281-290.

Chiodo, L.M., Jacobson, S.W., Jacobson, J.L., 2004. Neurodevelopmental effects of postnatal lead exposure at very low levels. Neurotoxicol. Teratol. 26, 359-371.

Chuang, H.Y., Cheng, W.C., Chen, C.Y., Yang, Y.H., Sung, F.C., Yang, C.Y., et al., 2008. A follow-up comparison of blood lead levels between foreign and native workers of battery manufacturing in Taiwan. Sci. Total Environ. 394, 52-56.

Coon, S., Stark, A., Peterson, E., Gloi, A., Kortsha, G., Pounds, J., et al., 2006. Wholebody lifetime occupational lead exposure and risk of Parkinson's disease. Environ. Health Perspect. 114, 1872-1876.

Diaz-Somoano, M., Kylander, M., López-Antón, M., Suarez-Ruiz, I., MartínezTarazona, M., Ferrat, M., et al., 2009. Stable lead isotope compositions in selected coals from around the world and implications for present day aerosol source tracing. Environ. Sci. Technol. 43, 1078-1085.

Dong, Y.H., Bai, J., Zhang, X.P., Chang, H., Zhang, X.J., Zhao, Y.R., 2001. Status and behavioral effect of lead poisoning for children 3-6 years in Shenyang (in Chinese). Gaungdong. Trace Elem. Sci. 8, 26-30.

Duan, X.L., 2012. Research Methods of Exposure Factors and its Application in Environmental Health Risk Assessment (in Chinese). Science Press, Beijing, Beijing, p. 31

Duan, X.L., Wang, Z.S., Li, Q., Zhang, W.J., Huang, N., Wang, B.B., et al., 2011. Health risk assessment of heavy metals in drinking water based on field measurement of exposure factors of Chinese people (in Chinese). Environ. Sci. 32, 1329-1339.

Fan, L., Chen, Y., Yang, H., Zhang, H., 2010. Lead pollution and its impact on children's blood lead concentration in a battery recycling (in Chinese). Chin. Prev. Med. 11, 76-78.

Fang, X., Tian, D.L., Xie, R.X., 2006. Soil physical and chemical properties of the wasteland in Xiangtan manganese mine (in Chinese). Acta Ecol. Sin. 26 1494-1501.

Fitzgerald, E.F., Schell, L.M., Marshall, E.G., Carpenter, D.O., Suk, W.A., Zejda, J.E. 1998. Environmental pollution and child health in Central and Eastern Europe. Environ. Health Perspect. 106, 307-311.

Fowler, B.A., 1993. Measuring Lead Exposure in Infants, Children, and Other Sensitive Populations. National Academy Press.

Gao, Y., Xia, J., 2011. Chromium contamination accident in China_ viewing environment policy of China. Environ. Sci. Technol. 45, 8605-8606.

Gil, F., Pla, A., 2001. Biomarkers as biological indicators of xenobiotic exposure. J. Appl. Toxicol. 21, 245-255.

Gottesfeld, P., Pokhrel, A.K., 2011. Review: lead exposure in batter manufacuring and recycling in developing countries and among children in nearby communities. J. Occup. Environ. Hyg. 8, 520-532.

Granero, S., Domingo, J.L., 2002. Levels of metals in soils of Alcala' de Henares, Spain : Human health risks. Environ. Int. 28, 159-164.

Guo, C.H., Zhu, Y.G., 2004. Contamination and availabile contents of heavy metals in soils in the typical minin and smelting circumjacent districts (in Chinese). Ecol. Environ. 13, 553-555.

Haefliger, P., Mathier-Nolf, M., Lociciro, S., Ndiaye, C., Coly, M., Diouf, A., et al., 2009 Mass lead intoxication from informal used lead acid battery recycling in Dakar, Senegal. Environ. Health Perspect. 117, 1535-1540.

Han, Y.M., Du, P.X., Cao, J.J., Posmentier, E.S., 2006. Multivariate analysis of heavy metal contamination in urban dusts of Xi'an, Central China. Sci. Total Environ. 355, 176-186.

He, K.M., Wang, S.Q., Zhang, J.L., 2009. Blood lead levels of children and its trend in China. Sci. Total Environ, 407, 3986-3993.

Hu, G., Wang, Z.B., Wu, L.B., Feng, H., Li, H.M., Hou, D.N., et al., 2002. Study on effects of battery recycling on environment and blood lead of children living in villages (in Chinese). Chin. Public Health 18, 1446-1448.

Hu, X., Zhang, Y., Ding, Z.H., Wang, T.J., Lian, H.Z., Sun, Y.Y., et al., 2012. Bioaccessibility and health risk of arsenic and heavy metals $(\mathrm{Cd}, \mathrm{Co}, \mathrm{Cr}, \mathrm{Cu}, \mathrm{Ni}, \mathrm{Pb}$, $\mathrm{Zn}$ and $\mathrm{Mn}$ ) in TSP and PM2.5 in Nanjing, China. Atmos. Environ. 57, 146-152.

Huang, P.C., Su, P.H., Chen, H.Y., Huang, H.B., Tsai, J.L., Huang, H.I., et al., 2012 Childhood blood lead levels and intellectual development after ban of leaded gasoline in Taiwan a 9-year prospective study. Environ. Int. 40, 88-96. 
IARC (International Agency for Research on Cancer), 2011. Agents Classified by the IARC Monographs, pp. 1-102.

Jamieson, J.A., Taylor, C.G., Weiler, H.A., 2006. Marginal zinc deficiency exacerbates bone lead accumulation and high dietary zinc attenuates lead accumulation at the expense of bone density in growing rats. Toxicol. Sci. 92, 286-294.

Ji, A., Wang, F., Luo, W.J., Yang, R.H., Chen, J.Y., Cai, T.J., 2011. Lead poisoning in China, a nightmare from industrialization. Lancet 377, 1474-1476.

Kaul, B., Sandhu, R.S., Depratt, C., Reyes, F., 1999. Follow-up screening of leadpoisoned children near an auto battery recycling plant, Haina, Dominican Republic. Environ. Health Perspect. 107, 917-920.

Koller, K., Brown, T., Spurgeon, A., Levy, L., 2004. Recent developments in low-level lead exposure and intellectual impairment in children. Environ. Health Perspect. 112, 987-994.

Kuijp, TJvd, Huang, L., Cheryy, C.R., 2013. Health hazards of China's lead-acid battery industry_ a review of its market drivers, production process, and health impacts. Environ. Health 61, 1-10.

Leung, A.O.W., Duzgoren-Aydin, N.S., Cheung, K.C., Wong, M.H., 2008. Heavy metals concentrations of surface dust from e-waste recycling and its human health implications in southeast China. Environ. Sci. Technol. 42, 2674-2680.

Li, Y., Wang, Y.B., Gou, X., Su, Y.B., Wang, G., 2006. Risk assessment of heavy metals in soils and vegetables around non-ferrous metals mining and smelting sites, Baiyin, China. J. Environ. Sci. 18, 1124-1134.

Liu, H.Y., Probst, A., Liao, B.H., 2005. Metal contamination of soils and crops affected by the Chenzhou lead_zinc mine spill (Hunan, China). Sci. Total Environ. 339, 153-166.

Liu, J.X., Wang, X.Y., Zeng, J., Chen, X., 2009. Comparison of lead concentration and isotope ratios in children's blood and hair. J. Hyg. Res. 38, 375-377.

Liu, Z.C., 2011. Contamination and Potential Risk Evaluation of Heavy Metals in the Major River Basin of Hunan (in Chinese). Agriculture. Master. Agricultural University of Hebei, Hebei.

Lopez, J.M., Callen, M.S., Murillo, R., Garcia, T., Navarro, M.V., Cruz, MTdl, et al., 2005 Levels of selected metals in ambient air PM10 in an urban site of Zaragoza (Spain). Environ. Res. 99, 58-67.

Mao, J.S., Lu, Z.W., Yang, Z.F., 2008. The Eco-efficiency of Lead in China's Lead-Acid battery system. J. Ind. Ecol. 10, 185-197.

Mari, M., Nadal, M., Schuhmacher, M., Domingo, J.L., 2009. Exposure to heavy metals and PCDD/Fs by the population living in the vicinity of a hazardous waste landfill in Catalonia, Spain: health risk assessment. Environ. Int. 35, 1034-1039.

Onianwa, P.C., Fakayode, S.O., 2000. Lead contamination of topsoil and vegetation in the vicinity of a battery factory in Nigeril. Environ. Geochem. Health 22 211-218.

Oomen, A.G., Hack, A., Minekus, M., Zeijdner, E., Cornelis, C., Schoeters, G., et al. 2002. Comparison of five in vitro digestion models to study the bioaccessibility of soil contaminants. Environ. Sci. Technol. 36, 3326-3334.

Pan, Y.M., Yang, G.Z., 1998. The Background Values of Soil in Hunan Province and its Research Methods (in Chinese). China Environ. Sci. Press, Beijing.

Qu, C.S., Ma, Z.W., Yang, J., Liu, Y., Bi, J., Huang, L., 2012. Human exposure pathways of heavy metals in a lead-zinc area, Jiangsu Province, China. PLoS One 7, e46793-46803.

Roth, D.E., Richard, S.A., Black, R.E., 2010. Zinc supplementation for the prevention of acute lower respiratory infection in children in developing countries_meta- analysis and meta-regression of randomized trials. Int. J. Epidemiol. 39, $795-808$.

Safar, Z., Labib, M.W., Gertler, A.W., 2014. Development and validation of a lead emision inventory for the Greater Cairo area. J. Adv. Res. 5, 511-562.

Soto-Jimenez, M.F., Flegal, A.R., 2011. Childhood lead poisoning from the smelter in Torreón, México. Environ. Res. 111, 590-596.

Sun, X.F., 2012. Study on pollution prevention and control of heavy metal in lead storage battery industry (in Chinese). Chin. Environ. Prot. Ind 11, 8-15.

Tian, X., Gong, Y., Wu, Y.F. Agyeiwaa, A., Zuo, T.Y., 2014. Management of used lead acid battery in China: secondary lead industry progress, policies and problems. Resour. Conserv. Recyl. 93, 75-84.

US EPA (United States Environmental Protection Agency), 1986. Guidelines for the health risk assessment of chemical mixtures. Fed. Regist. 51, 34014-34025.

US EPA (United States Environmental Protection Agency), 1997. Exposure Factors Handbook. 600. Office of Research and Development, Washington, DC, USA pp, EPA 95.

US EPA (United States Environmental Protection Agency), 2002. Supplemental Guidance for Developing Soil Screening Levels for Superfund Sites. Office of Solid Waste and Emergency Response, Washington, DC, USA, pp. 4-24 pp.

US EPA (United States Environmental Protection Agency), 2011a. Risk assessment Guidance for superfund. In: Part a: Human Health Evaluation Manual; Part E, Supplemental Guidance for Dermal Risk Assessment; Part F, Supplemental Guidance for Inhalation Risk Assessment, vol. I. EPA/540/1-89/002.

US EPA (United States Environmental Protection Agency), 2011b. Regional Screening Levels (RSL) Tables. Last updated June 2011.

Wang, H., Stuanes, A.O., 2003. Heavy metal pollution in air-water-soil-plant system of Zhuzhou City, Hunan Province, China. Water Air Soil Pollut. 147, 159-164.

Wang, J., Hu, Z.M., Chen, Y.Y., Chen, Z.L., Xu, S.Y., 2013. Contamination characteristics and possible sources of PM10 and PM2.5 in different functional areas of Shanghai, China. Atmos. Environ. 68, 221-229.

Wang, S.Q., Zhang, J.L., 2006. Blood lead levels in children, China. Environ. Res. 101, 412-418.

Wu, Y.H., Yang, X., Ge, J., Zhang, J., 2011. Blood lead level and its relationship to certain essential elements in the children aged 0 to 14years from Beijing, China. Sci. Total Environ. 409, 3016-3020.

Xia, Z.H., Duan, X.L., Qiu, W.X., Liu, D., Wang, B., Tao, S., et al., 2010. Health risk assessment on dietary exposure to polycyclic aromatic hydrocarbons (PAH) in Taiyuan. China 408, 5331-5337.

Xu, M., Zheng, J., Ruan, M., Wang, G., Zhang, Y., Yu, L., 2008. Comparison of the amounts of heavy metals ( $\mathrm{Pb}, \mathrm{As}, \mathrm{Cd}, \mathrm{Hg}$ )accumulated by different groups of vegetables (in Chinese). Acta Agric. Zhejiangensis 20, 29-34.

Zeleny, R., Emteborh, H., Charoud-Got, J., Schimmel, H., Nia, Y., Mutel, I., Ostyn, A., Herbin, S., Hennekinne, J.A., 2015. Development of a reference material for staphylococcus aureus enterotoxin A in Cheese: feasibility study, processing, homogeneity and stability assessment. Food. Chem. 168, 241-246.

Zhang, L.L., Xu, R.J., Wu, G.P., Wei, F.S., 2010. Determination of trace elements in soil in Xuanwei and Fuyuan by microwave digestion-ICP-MS. Environ. Monit. China 26, 6-10.

Zheng, N., Liu, J.S., Wang, Q.C., Liang, Z.Z., 2010. Health risk assessment of heavy metal exposure to street dust in the zinc smelting district, Northeast of China. Sci. Total Environ. 408, 726-733. 